\title{
Evaluation of Psychoacoustic Annoyance and Perception of Noise Annoyance Inside University Facilities
}

\author{
Edgar Tristán-Hernández \\ Universidad Autónoma de San Luis Potosí, México. Facultad de Ciencias, Campus Pedregal. Av. Chapultepec \\ 1570, Privadas del Pedregal.
}

\author{
Ignacio Pavón García and Juan Manuel López Navarro \\ Instrumentation and Applied Acoustics Research Group (I2A2), Polytechnic University of Madrid (UPM), Campus \\ Sur, Carretera de Valencia, km. 7, 28031 Madrid.
}

\author{
Isaac Campos-Cantón \\ Universidad Autónoma de San Luis Potosí, México. Facultad de Ciencias, Campus Pedregal. Av. Chapultepec \\ 1570, Privadas del Pedregal.
}

\begin{abstract}
Eleazar Samuel Kolosovas-Machuca
Universidad Autónoma de San Luis Potosí, Coordinación para la Innovación y la Aplicación de la Ciencia y la Tecnología. Sierra Leona 550, Lomas2 ${ }^{d a}$ Sección, 78210, San Luís Potosí, San Luis Potosí, México.
\end{abstract}

\begin{abstract}
(Received 20 March 2015; accepted 10 February 2016)
The levels of noise produced in university facilities by students, increases the noise annoyance. The quality of life and the academic performance of university students could be inuenced by this factor. Unfortunately, as far as methodology is concerned, there are no regulations or standards that allow for the correct evaluation of noise annoyance at educative facilities. In this work a method for the evaluation of noise annoyance and an indicator of noise annoyance are presented. In order to obtain a numerical value, a percentage index, and a verbal index that represents the noise annoyance in a specific area at university facilities, psychoacoustic annoyance (PA) and evaluation of perception of noise annoyance has been related. Resulting from this correlation an indicator of noise annoyance was proposed. The results were associated with this indicator. The method and the proposed indicator allow for deeper evaluation of noise annoyance and facilitate the development of appropriate actions against noise.
\end{abstract}

\section{INTRODUCTION}

The impact of noise on the quality of life of people is a topic of interest of many researchers. The works on this topic mainly focused on studying noise annoyance produced by urban sources and its inuence on quality of life, and the physical and psychological health of the general population. ${ }^{1-5}$ However, noise annoyance inside educational facilities at the university level is a topic that has not been deeply studied. Topics such as background noise levels in classrooms, speech intelligibility, isolation, and acoustic conditioning specically inside classrooms are the main study areas. ${ }^{6-9}$ There are several factors that inuence the increase of noise in these places. Inside university facilities, the students themselves are the main source of noise. Throughout the day, students are involved in many activities inside the university facilities. At the university, usually, there are places with a large mass of students. This is why noise increases signicantly and, consequently, the noise annoyance as well. ${ }^{10}$ This problem is worst mainly in places with inexistent acoustic treatment like common halls and hallways. Typically, noise annoyance is a parameter evaluated with objective and subjective methods, but currently, there are no regulations to evaluate this parameter. This is the reason why different methods to determine annoyance are used in many studies. ${ }^{1,2,4,11-20}$ However, the method described by Fastl and Zwicker ${ }^{21}$ is used in many studies. This method is based on the calculation of psychoacoustic parameters such as loudness, roughness, sharpness, and uctuation strength. These four parameters result in another parameter that evaluates the annoyance known as psychoacoustic annoyance (PA). On the other hand, another typical method is based on listening tests in combination with the application of questionnaires. ${ }^{22-25}$ Different kinds of questionnaires and different scales of evaluation were used in the existing studies..$^{1,3,5,26}$ However, to standardize the evaluation of the response to noise, the International Commission of the Biological Effects of Noise (ICBEN) established a method based on a survey that was developed in different languages. ${ }^{27}$ This survey is the result of the collaboration of different researchers from around the world and consists of two questions; each one of them has different scales (a 5-point verbal scale and an 11-points numerical scale), which will be explained later. Because of the importance of the effects of noise on health, quality of life, and school performance of university students, the noise sources and acoustic conditions in areas where students usually develop their daily activities should be studied. In addition, it is essential to develop the mechanisms that study and develop strategies and regulations applicable to students, an important population group. 
This could help protect students from the effects of noise on their physical and psychological health, and consequently improve their school performance. In this work, a methodological proposal to evaluate noise annoyance at university facilities is presented. The results were correlated and represented in a graphic colour scale.

\section{METHOD}

This work involved a study of the noise conditions in university facilities. The methodology proposed requires an acoustic analysis using data obtained from the recordings of specic sound environments. This was done using the method of evaluation of the PA proposed by Fastl and Zwicker. ${ }^{20}$ Second, an assessment directly derived from the perception of noise of students was carried out. This was developed through the combination of the application of a listening test and a noise annoyance questionnaire based on the standardized generalpurpose noise reaction questions for community noise surveys proposed by ICBEN. ${ }^{26}$ To obtain two related noise indexes, the results of the two methods mentioned previously were correlated. These indexes, called "percentage noise annoyance index" (PNAI) and "verbal noise annoyance index" (VNAI), indicate a conclusive percentage value and a verbal value incorporated and represented in a graphic colorcolour scale that helps to identify the level of noise annoyance in a specic place.

\subsection{Participants}

A total of 33 students (17 male and 16 female) between 19 and 34 years old participated in the experiment. Twelve of the participants were degree students, 9 were master students, and 12 were doctorate students. Before the trial, the current state of participants' auditory health was evaluated according to the International Organization for Standardization Acoustics. ${ }^{28}$ The participants did not exceed $20 \mathrm{~dB}$ in the frequency range of $125-8 \mathrm{kHz}$.

\subsection{Selection and Recording of Sound Envi- ronments}

The audio recordings completed at the places where students usually conduct their study activities have been used for this experiment. These locations include: a classroom during an exam, a classroom during a normal lesson, a hallway adapted for studying, a library, a computer room, and a common hall also adapted for studying. The sound environments were recorded using a Zoom H4n Handy Recorder previously calibrated in controlled acoustic conditions (anechoic chamber). The file format used was a WAV file at 16-bit, $44.1 \mathrm{kHz}$, and the length of each sound environment recorded was two minutes long. The output level also was calibrated in an anechoic chamber using the Bruel and Kjr head and torso simulator (HATS) Type 4128D and Pulse platform. The audios were reproduced using Pro Tools D9 software for Mac, a sound card Mackie Onyx Satellite, and headphones (model AKG K142 HD). The listening tests were carried out inside an audiometric chamber. The total time spent on each test lasted 12 minutes.

\subsection{Evaluation of PA}

The recordings and their subsequent analysis were performed using the psychoacoustic analyser Brel and Kjr Sound Quality type 7698. Psychoacoustic metrics, such as loudness $(N)$, specic loudness $\left(N_{0}\right)$, sharpness $(S)$, roughness $(R)$, and
Table 1. Verbal answer and numeric scale for the annoyance question (5-point scale).

\begin{tabular}{|c|c|}
\hline Verbal answer recommended & Numeric scale \\
\hline a) Not at all & 0 \\
\hline b) Slightly & 21.93 \\
\hline c) Moderately & 47.34 \\
\hline d) Very & 73.39 \\
\hline e) Extremely & 97.72 \\
\hline
\end{tabular}

uctuation strength $(F S)$, were obtained. These parameters are related to describe quantitatively the PA from the information obtained in the laboratory, the method proposed by Fastl and Zwicker. ${ }^{21}$ The PA value is obtained using the following equation:

$$
P A=N_{5}\left(1+\sqrt{W_{S}^{2}+W_{F R}^{2}}\right) .
$$

Where $N_{5}$ is the percentile 5 of loudness, $W_{S}$ is the component where sharpness $(S)$ is included,

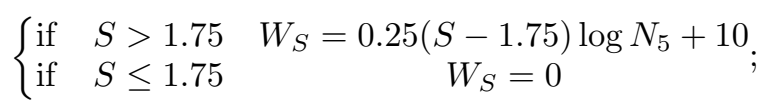

$W_{F R}$ is the modulation component where fluctuation strength $(F S)$ and roughness $(R)$ are included.

$$
W_{F R}=\frac{2.18}{N_{5}^{0.1}}(0.4(F S)-0.6 R) .
$$

\subsection{Perception of Noise Annoyance}

The method to evaluate the perception of noise annoyance is normally through listening tests and surveys. This questionnaire consisted of two questions related to noise annoyance based on the questions recommended by ICBEN. ${ }^{26}$ Likewise, two answer scales are proposed for these two questions: a 5-point verbal scale and 0-10 numeric scale (11-point scale). These scales have been used because a slight difference of perception between a numerical scale and a verbal scale could exist. The participants were questioned about the noise conditions inside the facilities recorded previously. The questionnaire was applied to the students while they were listening to the recording inside an audiometric room and they did the test only once. They were asked to take enough time to listen to the recordings before starting to answer the questions to have a better sensation of the sounds presented. For the 5-point verbal scale (see Table 1), the question was, "In this recording, how much does the environmental sound bother, disturb, or annoy you: extremely, very, moderately, slightly, or not at all $\underset{i}{ }$ " Numerical values have been assigned to each specic score in the 5-point verbal scale, proposed in the standardized generalpurpose noise reaction questions for community noise surveys for Spanish language given by ICBEN27 (Table 1).

The question for the 11-point scale (see Fig. 1) was, "Next is a zero-to-ten opinion scale for how much the environmental sound heard in the recording bothers, disturbs, or annoys you. If you are not at all annoyed, choose zero; if you are extremely annoyed, choose ten; if you are somewhere in between, choose a number between zero and ten."

\subsection{Numerical, Percentage, and Verbal Noise Annoyances Indexes}

To have a variable that allows the classication of sound environment according to the level of annoyance, two correlated 


\section{Not at all $\square \square \square \square \square \square \square \square \square \square \square$ Extremely $\begin{array}{lllllllllll}0 & 1 & 2 & 3 & 4 & 5 & 6 & 7 & 8 & 9 & 10\end{array}$}

Figure 1. Numeric answer scale for the annoyance question (11-point scale).

Table 2. Relationship between numerical index (NNAI), percentage index (PNAI) and verbal index (VNAI).

\begin{tabular}{|c|c|c|}
\hline $\begin{array}{c}\text { Numerical Index } \\
\text { - NNAI }\end{array}$ & $\begin{array}{c}\text { Percentage Index } \\
- \text { PNAI }\end{array}$ & $\begin{array}{c}\text { Verbal index } \\
- \text { VNAI }\end{array}$ \\
\hline $0-3.60$ & $0 \%-3.6 \%$ & Not at all \\
\hline $3.61-23.55$ & $3.61 \%-23.55 \%$ & Slightly \\
\hline $23.56-58.62$ & $23.56 \%-58.62 \%$ & Moderately \\
\hline $58.63-89.77$ & $58.63 \%-89.77 \%$ & Very \\
\hline $89.78-100$ & $89.78 \%-100 \%$ & Extremely \\
\hline
\end{tabular}

variables have been proposed: one percentage index and one verbal index. Resulting from the mean of the results between the evaluation of the PA and the evaluation of perception of noise annoyance, a numerical index is obtained and called numerical noise annoyance index (NNAI). Because NNAI is numerical data represented on a scale of 0 to 100 points, it is possible to transpose and express it directly in percentage terms. Thus it is possible to obtain an index which is called percentage noise annoyance index (PNAI). Furthermore, a verbal index called verbal noise annoyance index (VNAI) is directly related to the numerical ranges given on the scale of reaction to noise proposed by ICBEN ${ }^{22}$ and according to the numerical value obtained from the mean of the results between the evaluation of psychoacoustic annoyance (PA) and that of the perception of noise annoyance (Table 2).

\section{RESULTS}

\subsection{Evaluation of PA}

The evaluation of the PA was performed according to the method described previously in section 2.3. This research is not focused on the particular study of each one of the psychoacoustic parameters because the main variable to be studied is the PA formulated by Fastl and Zwicker. ${ }^{21}$ However, as described previously, to obtain this variable, it is necessary to obtain known psychoacoustic parameters such as loudness $(N)$, specic loudness $\left(N^{\prime}\right)$, sharpness $(S)$, roughness, and uctuation strength $(F S)$. To obtain these parameters, the six sound clips were recorded with HATS. The recordings and the subsequent analysis of the clips were performed using the psychoacoustic analyser Brel and Kjaer Sound Quality Type 7698. Table 3 summarizes the results of this analysis for all clips recorded, and Fig. 2 shows the one-third octave spectrum of all environments as reported by Tristn et al. ${ }^{29}$ The equivalent total level $\left(L_{A e q, T}\right)$ of these sound environments oscillates from 68.1 and 83.5 dBA. For loudness, it is possible to observe that the minimum and maximum values correspond to the classroom during an exam (16.55 sones) and the common hall (46.75 sones), respectively. For sharpness, the minimum level was observed in the common hall (1.31 acum), and the maximum level was seen in the classroom during an exam (1.65 acum). In the case of roughness, it has been possible to observe the minimum and maximum values in the computer room (1.57 asper) and the classroom during an exam (1.70 asper), respectively. The minimum value of uctuation strength was registered in the common hall (1.28 vacil), whereas the computer room is the place with the maximum value (2.07 vacil). Finally, the minimum

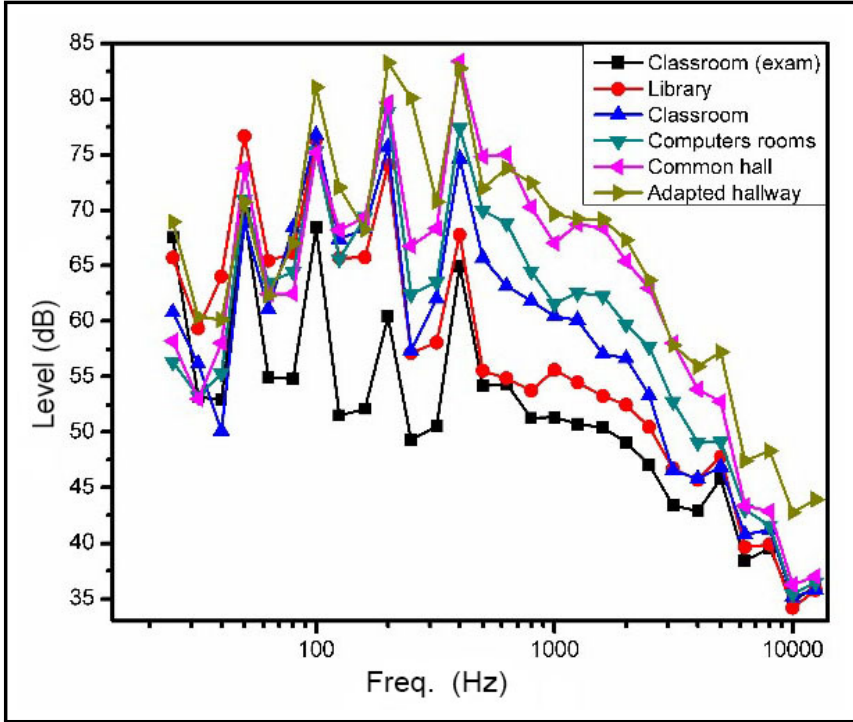

Figure 2. One-third octave band spectra of each sound environment.

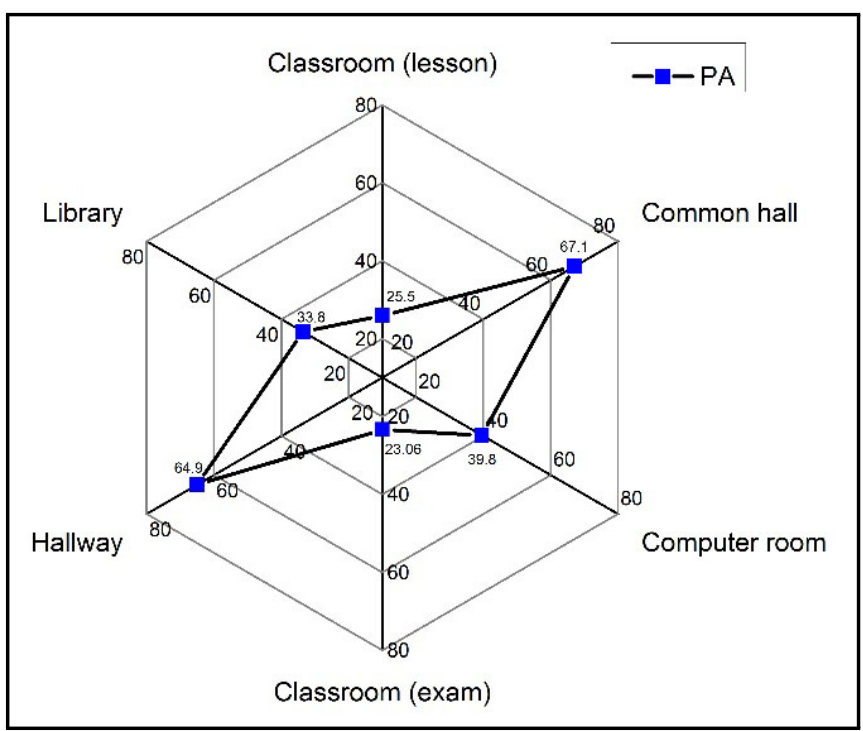

Figure 3. Psychoacoustic annoyance value for each sound environment.

and maximum values of specic loudness $(N)$ correspond to the classroom during an exam ( 0.75 sones/Bark) and the hallway (2.25 sones/Bark), respectively.

Thus, in evaluating and performing according to the method described in III, the results show that the sound environment with a higher value of PA corresponds to the hallway ( $\mathrm{PA}=6$ 4.99 ) and the common hall $(\mathrm{PA}=67.09)$. On the other hand, the lowest values of PA correspond to the classroom during a lesson $(\mathrm{PA}=25.96)$ and the classroom during an exam $(\mathrm{PA}=$ 23.34). The computer room obtained a PA value of 39.6 , and the library, with a PA value of 33.5 , is also an environment with low PA (Fig. 3).

\subsection{Evaluation of the Perception of Noise Annoyance}

\subsubsection{Relation Between ICBEN 5-Point verbal scale and 11-Point Numerical Scale.}

The results show that participants perceive that the common hall (63.04 points) and the hallway (57.56 points) are the most annoying places. Conversely, the classroom during an exam (5.31 points) and the classroom during a normal lesson 


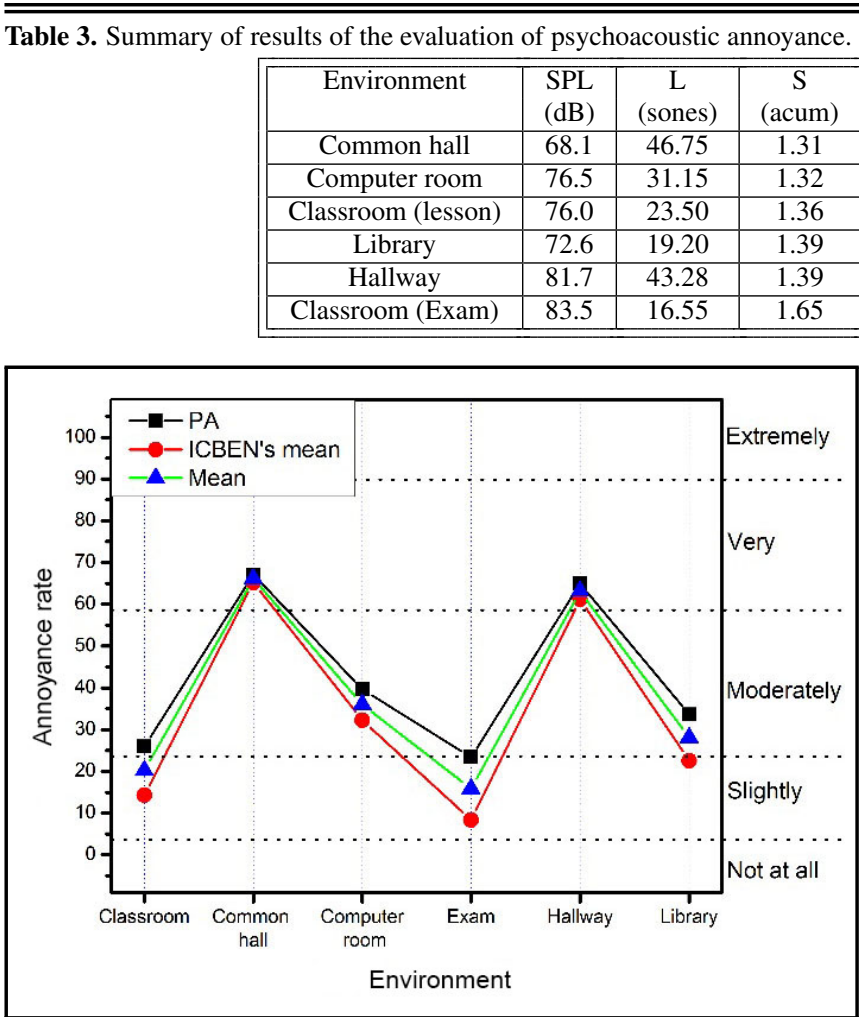

Figure 4. Comparison between results of the evaluation of perception of noise.

(14.06 points) are the less annoying places. Table 4 summarizes the results of the question related to the ICBEN 5-point verbal scale. On the other hand, according to the results for the ICBEN 11-point numerical scale, the classroom during an exam is the place with the lowest annoyance (4.54 points). On the other hand, the common hall is the place that participants perceive as the most annoying place of all the environments (67.27 points). A summary of the descriptive statistics is shown in Table 4.

Thus, to determine if obtained results between both 5- and 11-point scales (referred to as ICEBEN 5 and ICBEN 11, respectively) are directly related, a statistical analysis was performed. According to the Kolmogorov-Smirnov test, the differences between both 5- and 11-point scales of all sound environments (except for the classroom during an exam) present a normal distribution; therefore, a t-test for related samples was carried out. For the classroom during an exam, a repeatedmeasures ANOVA with a Greenhouse-Geisser correction was used. The related measures t-test revealed that in the case of the classroom, no signicant differences $(t(32)=0.166, p=0.869)$ between ICBEN 5 (14.0612.31) and ICBEN 11 (14.5511.75) were found. Likewise, for the common hall, no signicant differences $(t(32)=1.753, p=0.089)$ between ICBEN 5 (14.0612.31) and ICBEN 11 (14.5511.75) were found. Furthermore, no signicant differences $(t(32)=0.696, p=0.491)$ for the computer rooms between ICBEN 5 (31.1712.41) and ICBEN 11 (33.3310.80) were found. The mean of the differences of the classroom during an exam between the two tests, ICBEN 5 (5.319.54) and ICBEN 11 (4.545.64), were not signicantly different $(t(32)=0558, p=0.581)$. Differences in the hallway between ICBEN 5 (57.5622.95) and ICBEN 11 $(64.8527 .17)$ also were not signicant $(t(32)=0.147, p=0.147)$. In the case of the library, it also was possible to observe no signicant differences $(t(32)=0.435, p=0.667)$ between ICBEN 5 (27.7323.48) and ICBEN 11 (23.3317.79). Finally, for the classroom during an exam, the repeated-measures ANOVA test

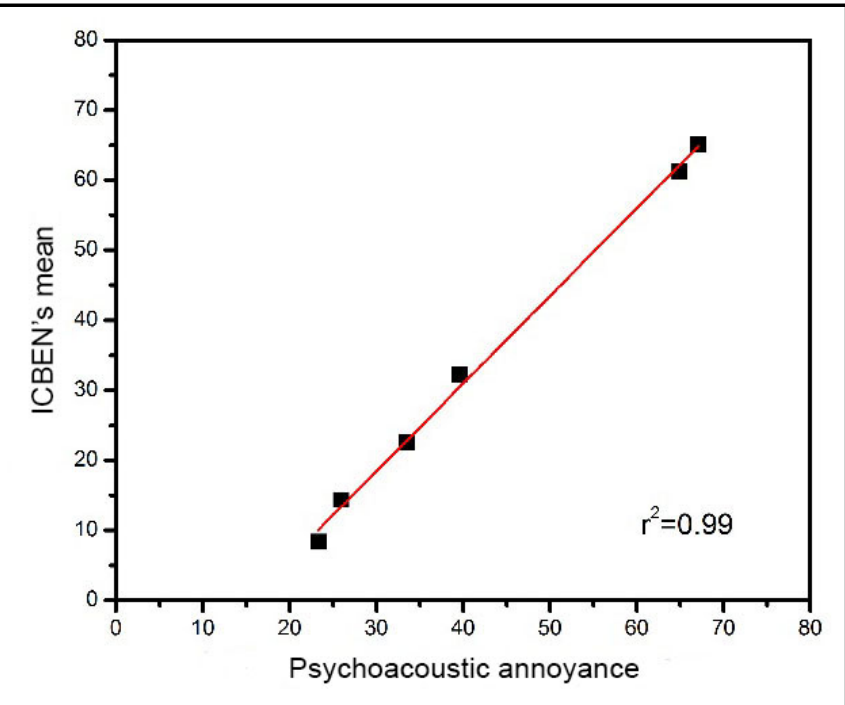

Figure 5. Correlation between evaluation of perception of noise annoyance (ICBEN's mean) and Psychoacoustic Annoyance (PA).

shows no signicant differences $(F(1,32)=0.311, p=0.581)$. Furthermore, the comparison and the mean value between both 5- and 11-point scales of each environment are shown in Table 4 .

\subsection{Numerical, Percentage, and Verbal Noise Annoyances Indexes}

A numerical variable was obtained from the comparison of the means carried out between the results derived from the mean of both 5- and 11-point annoyance scales and evaluation of the PA. This variable has been called numerical noise annoyance index (NNAI). A graphical comparison of both variables is shown in Fig. 4. Likewise, Table 5 summarizes the results obtained from each sound environment and the allocation of the verbal noise annoyance index (VNAI), which directly depends on the numerical noise annoyance index (NNAI) obtained. Also, the percentage noise annoyance index (PNAI) is shown. In addition, has been changed to verify that the numerical noise annoyance index (NNAI) is a signicant value, a Pearson correlation was used to check whether a signicant correlation exists between both annoyance scale variables. The Pearsons $r$ correlation shows a clear positive correlation between both variables: $r=0.999, p<0.01$ (Fig. 5).

\section{INDICATOR OF NOISE ANNOYANCE LEVEL}

An indicator of the level of noise annoyance represented in a colour scale is proposed. This scale of annoyance is graphically represented in an indicator, where the colour levels according to the percentage index and verbal index is combined (Fig. 6). This indicator has five levels of colours (green, blue, yellow, orange, and red) that are used and related cboxto the 
Table 4. Summary of descriptive statistics of the evaluation of the perception of noise annoyance.

\begin{tabular}{|c|c|c|c|c|c|c|c|c|c||}
\hline \multirow{2}{*}{ Sound environment } & \multicolumn{4}{|c|}{ 5-points verbal scale } & \multicolumn{4}{|c|}{ 11-points numerical scale } \\
\cline { 2 - 8 } & Min. & Max. & S.D. & Mean & & Mean & S.D. & Max. & Min. \\
\hline Classroom & .00 & 47.34 & 12.31 & 14.06 & $\mathbf{1 4 . 3 0}$ & 14.54 & 11.75 & 40 & .00 \\
\hline Common hall & 21.93 & 97.72 & 16.88 & 63.04 & $\mathbf{6 5 . 1 6}$ & 67.27 & 21.10 & 100 & 20 \\
\hline Computer room & 21.93 & 47.34 & 12.41 & 31.17 & $\mathbf{3 2 . 2 5}$ & 33.33 & 10.80 & 60 & 20 \\
\hline Classroom (exam) & .00 & 21.93 & 9.543 & 5.31 & $\mathbf{4 . 9 3}$ & 4.54 & 5.64 & 20 & .00 \\
\hline Hallway & 21.93 & 97.72 & 22.95 & 57.56 & $\mathbf{6 1 . 2 0}$ & 64.84 & 27.17 & 100 & .00 \\
\hline Library & .00 & 73.39 & 23.48 & 21.73 & $\mathbf{2 2 . 5 3}$ & 23.33 & 17.79 & 70 & .00 \\
\hline
\end{tabular}

Table 5. Summary of results for each sound environment obtained from the evaluation.

\begin{tabular}{|c|c|c|c|c|c|c|}
\hline $\begin{array}{c}\text { Sound } \\
\text { environment }\end{array}$ & PA & $\begin{array}{c}\text { ICBENs } \\
\text { mean }\end{array}$ & Difference & $\begin{array}{c}\text { Mean } \\
\text { (NNAI) }\end{array}$ & PNAI & VNAI \\
\hline Classroom & 25.96 & 14.30 & -11.6600 & 20.13 & $20.1 \%$ & Slightly \\
\hline Common hall & 67.09 & 65.16 & -1.929993 & 66.12 & $66.1 \%$ & Very \\
\hline Computer room & 39.60 & 32.25 & -7.329998 & 35.92 & $35.9 \%$ & Moderately \\
\hline Classroom (exam) & 23.34 & 8.31 & -16.6900 & 15.82 & $15.8 \%$ & Slightly \\
\hline Hallway & 64.99 & 61.21 & -3.77999 & 63.10 & $63.1 \%$ & Very \\
\hline Library & 33.57 & 22.53 & -11.0400 & 28.05 & $28.0 \%$ & Moderately \\
\hline
\end{tabular}

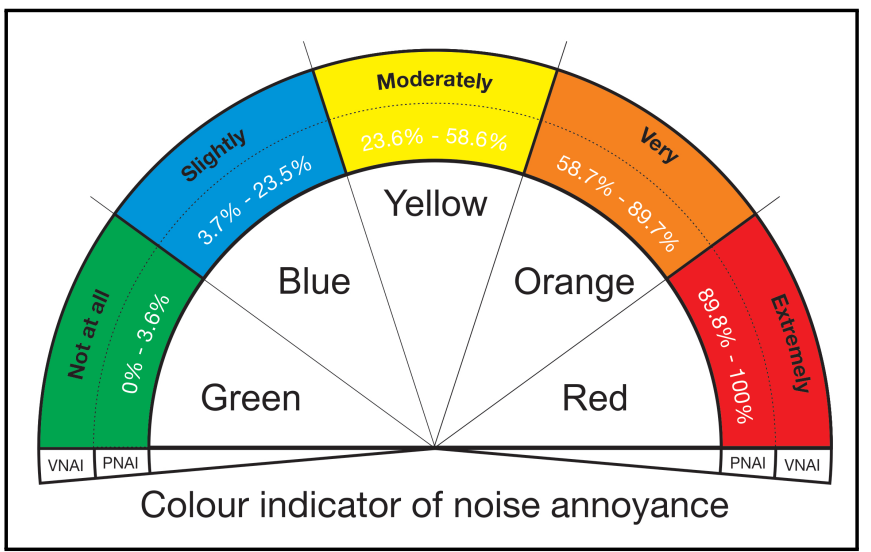

Figure 6. Proposed color indicator of level of noise annoyance.

percentage noise annoyance index (PNAI) which is derived for the numerical noise annoyance index (NNAI) and also with the verbal noise annoyance index (VNAI) (see section 3). Considering the importance of unifying criteria for the evaluation of noise annoyance, the ranks of this colour scale are based on the 5 -point scale described previously (Table 1) in reaction modier given by ICBEN. ${ }^{21}$

\section{CONCLUSIONS}

In this work, a method to evaluate noise annoyance in university facilities has been proposed. This method was based on the comparison and correlation of two known methods to evaluate noise annoyance, the PA, ${ }^{15}$ and the evaluation of perception of noise annoyance through listening tests, on the basis of the method described by ICBEN. ${ }^{21}$ The results from the evaluation of perception of noise annoyance show that between the answers of both rating scales (5-point and 11-point), there were no statistically signicant differences; this means that there is an important relation between the answers of both scales. Thus, derived from the mean of both tests, it has been viable to determine a numerical value that represents noise annoyance in a specic place. Furthermore, the recordings of six sound environments inside university facilities were studied. Psychoacoustic parameters were obtained, and it was possible to determine a specic value for the PA. A numerical variable, named numerical noise annoyance index (NNAI), was obtained from the comparison of the means between the results derived from both 5- and 11-point annoyance scales and the PA. This variable gives us a numerical value to represent the level of noise annoyance in a specic sound environment. During this study, it has been possible to observe that classrooms and libraries are not the only places used for study activities. Many other places, such as hallways, halls, and gardens, are employed as study places in an improvised way and used for study activities and for socialization with other students. The results of this study show that these places are the most annoying. The data collected from this study provides important information about the conditions where students develop their study activities. It makes the development of the most adequate strategies against noise easier. It is well known that acoustic conditioning is the most expensive action. Consequently, nding cheap and reliable alternatives is necessary. Thus, a colour indicator of noise annoyance has been proposed. The variables from this methodology have been summarized. This indicator serves as a tool to facilitate the classication of a particular sound environment according to their level of noise annoyance and also for designing strategies against noise. The method and the colour indicator proposed in this work will allow a deeper evaluation of noise annoyance and also facilitate the development of strategies and appropriate actions against noise.

\section{AKNOWLEDGEMENTS}

The first author would like to acknowledge the Mexican Council of Science and Technology, (CONACYT) for the financial support given to develop this project, as well as Universidad Autnoma de San Luis Potos and Universidad Politcnica de Madrid.

\section{REFERENCES}

1 Paunović, K. Noise annoyance in adult urban population: a discrepancy between theory and practice, Acta Medica Medianae, 52 (3), 12-17, (2013). https://dx.doi.org/10.5633/amm.2013.0302

2 Sobotová, L., Jurkovičová, J., S̆tefániková, Z., Ševčíková, L., and Ághová, L. Community noise annoyance assessment in an urban agglomeration, Bratisl Lek Listy, 107 (5), 214-216, (2006). https://dx.doi.org/10.1097/00001648200611001-01367

3 Botteldooren, D., Dekoninck, L., and Gillis, D. The inuence of trafc noise on appreciation of the living quality 
of a neighbourhood, International Journal of Environmental Research and Public Health, 8 (3), 777-798, (2011). https://dx.doi.org/10.3390/ijerph8030777

4 Héritier, H., Vienneau, D., Frei, P., Eze, I.C., Brink, M., Probst-Hensch, N., and Röosli, M. The association between road trafc noise exposure, annoyance and health-related quality of life (HRQOL). Int. J. Environ. Res. Public Health, 11, 12652-12667, (2014). https://dx.doi.org/10.3390/ijerph111212652

5 Van den Berg, F., Verhagen, C., and Uitenbroek, D. The relation between scores on noise annoyance and noise disturbed sleep in a public health survey, Int. J. Environ. Res. Public Health, 11 (2), 2314-2327, (2014). https://dx.doi.org/10.3390/ijerph110202314

6 Crandell, C. Classroom acoustics for hearing-impaired children, Journal of the Acoustical Society of America, 92, 2470, (1992). https://dx.doi.org/10.1121/1.404481

7 Crandell, C. and Smaldino, J. Classroom acoustics for children with normal hearing and with hearing impairment, Language, Speech, and Hearing Services in Schools, 31, 362-370, (2000). https://dx.doi.org/10.1044/01611461.3104 .362

8 Knecht, H., Nelson, P., Whitelaw, G., and Feth, L. Background noise levels and reverberation times in unoccupied classrooms: predictions and measurements, American Journal of Audiology, 11, 65-71, (2002). https://dx.doi.org/10.1044/1059-0889(2002/009)

9 Hodgson, M., Rempel, R., and Park, E. Measurement of typical speech and background-noise levels in university classrooms during lectures, NOISE-CON, id. ant, (1997). https://dx.doi.org/10.1121/1.418753

10 Hernández, E., García, I., Navarro, J. and KolosovasMachuca, E. Evaluation of noise environments during daily activities of university students, International Journal of Occupational Safety and Ergonomics, pp.1-5, (2016)

11 Jekosch, U. Meaning in the context of sound quality assessment, Acta Acustica united with acustica, 85 (5), 681-684, (1999).

12 Fastl, H. Neutralizing the meaning of sound for sound quality evaluations, Proceedings 17th International Congress of Acoustics (ICA), Rome, Italy, (2001).

13 Ellermeiera, W., Zeitlera, A., and Fastl, H. Predicting annoyance judgments from psychoacoustic metrics: identiable versus neutralized sounds, Proceedings of the The 33 rd International Congress and Exposition on Noise Control Engineering, Internoise, Prague, (2004).

14 Willemsen, A. M. and Mohan, D. Characterization of sound quality of impulsive sounds using loudness based metric, Proceedings of the 20th International Congress on Acoustics (ICA), 23-27 August, Sydney, Australia, (2010). https://dx.doi.org/10.1260/1351-010x.17.1.85

15 Fastl, H. Psychoacoustics and sound quality, Communication Acoustics, Springer-Verlag, Berlin, Heidelberg, 139162, (2005). https://dx.doi.org/10.1007/3-540-27437-5_6
16 Fastl, H. From psychoacoustics to sound quality engineering, Proceedings of the Institute of Acoustics, Coventry, 143-156, (2003).

17 Fastl, H. Recent developments in sound quality evaluation, Proc. Forum Acusticum, 1647-1653, (2005).

18 Kaczmarek, T. and Preis, A. Annoyance of time-varying road trafc noise, Archives of Acoustics, 35 (3), 383-393, (2010). https://dx.doi.org/10.2478/v10168-010-0032-2

19 Nor, M. J. M., Fouladi, F.H., Nahvi, H., and Arifn, A.K. Index for vehicle acoustical comfort inside a passenger car, Applied Acoustics, 69, 343-353, (2008). https://dx.doi.org/10.1016/j.apacoust.2006.11.001

20 Sandrock, S., Griefahn, B., Kaczmarek, T., Hafke, H., Preis, A., and Gjestland, T. Experimental studies on annoyance caused by noises from trams and buses, Journal of Sound and Vibration, 313, 908-919, (2008). https://dx.doi.org/10.1016/j.jsv.2007.12.003

21 Fastl H. and Zwicker E. Psychoacoustics: facts and models. Springer-Verlag, Berlin. (2007). https://dx.doi.org/10.1007/978-3-540-68888-4

${ }^{22}$ Leite, R.P., Paul, S., and Gerges, S.N.Y. A sound qualitybased investigation of the HVAC system noise of an automobile model, Applied Acoustics, 70, 636-645, (2009). https://dx.doi.org/10.1016/j.apacoust.2008.06.010

23 Goujard, B., Sakout, A., and Valeau V. Acoustic comfort on board ships: an evaluation based on a questionnaire. Applied Acoustics, 66, 1063-1073, (2005). https://dx.doi.org/10.1016/j.apacoust.2005.01.001

24 Jeon, J.Y., You, J., and Chang, H.Y. Sound radiation and sound quality characteristics of refrigerator noise in real living environments, Applied Acoustics, 68, 1118-1134, (2007). https://dx.doi.org/10.1016/j.apacoust.2006.06.005

25 Boman, E. and Enmarker, I. Factors affecting pupils noise annoyance in schools: the building and testing of models, Environment and Behaviour, 36, 207-228, (2004). https://dx.doi.org/10.1177/0013916503256644

26 Fields, J.M. An update catalogue of 521 social surveys of residents reactions to environmental noise (19432000) NASA/CR-2001-211257, National Aeronautics and Space Administration, Washington, DC., (2000).

27 Fields, J.M. Standardized general-purpose noise reaction questions for community noise surveys: research and a recommendation, Journal of Sound and Vibration, 242 (4), 641-679, (2001). https://dx.doi.org/10.1006/jsvi.2000.3384

28 International Organization for Standardization (ISO) Acoustics. Audiometric test methods, part 1: pure-tone air and bone conduction threshold audiometry (Standard No. ISO 8253-1:2010 (en)), Genve, Switzerland: ISO, (2010).

29 Tristán, E., Pavón, I., and López, J. M. Evaluation of acoustic quality in university facilities, Proceedings of ISMA2012-USD2012 Conference, Leuven, Belgium, 12491262, (2012). 